\title{
Erratum to: Validating a human model for anxiety using startle potentiated by cue and context: the effects of alprazolam, pregabalin, and diphenhydramine
}

\author{
J. M. P. Baas • N. Mol • J. L. Kenemans • \\ E. P. Prinssen • I. Niklson • C. Xia-Chen • F. Broeyer • \\ J. van Gerven
}

Published online: 24 April 2010

(C) Springer-Verlag 2010

Erratum to: Psychopharmacology (2009) 205:73-84

DOI 10.1007/s00213-009-1516-5

The original version of this article unfortunately contained a mistake. The graph from Figure 1 was also used for Figure 2.

The correct image for Figure 2 is shown below.

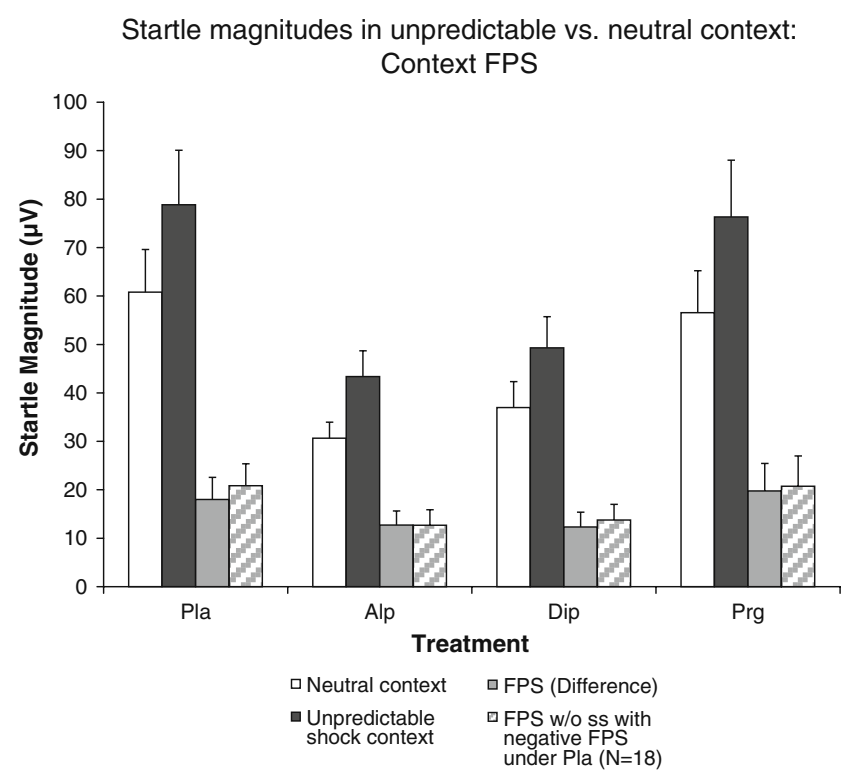

Fig. 2 Startle magnitudes in the unpredictable versus neutral contexts reflecting context FPS. Error bars are standard error of the mean. Pla placebo, Alp alprazolam, Dip diphenhydramine, Prg pregabalin

C. Xia-Chen · F. Broeyer • J. van Gerven Centre for Human Drug Research,

Leiden, The Netherlands

Present Address:

I. Niklson

Swissmedic,

Bern, Switzerland

Basel, Switzerland 